\title{
MATHEMATICS AND THE NATIONAL SCIENCE FOUNDATION
}

(A statement by the policy Committee for Mathematics based upon a report of the Committee on the Needs of Mathematics which can be met by a National Science Foundation.)

It is essential that the greatest flexibility be maintained in the adminstration of the funds which are made available for mathematics by the National Science Foundation. We feel that the charge of the Mathematics Division of the National Science Foundation, and of any advisory committee which is established should be to advance the welfare of mathematics. The means of doing this should remain a constantly evolving process.

With this in mind we make the following recommendations.

I. Immediately mathematicians should, through the Policy Committee, take steps to insure:

A. That persons are appointed to Foundation posts-both on the Foundation itself and in the responsible Civil Service positionswho are competent and persons of good judgment. We recommend that the Policy Committee inform the proper authorities in Washington, that the Policy Committee holds itself ready to consult with them on matters affecting mathematics connected with the establishment of a Foundation, is concerned to see that competent persons are appointed to the posts in the two roles mentioned above, and in particular wishes to suggest suitable nominations for Membership on the Foundation.

B. A Division of Mathematics of the National Research Council is established whose principal jobs with respect to the Foundation would be to:

1. take whatever steps are appropriate to secure a proper budget for mathematics. Here an assessment of the need should be made carefully, taking account of available talent, and of fields which lie outside the principal interests of organized mathematics, but will not receive support elsewhere;

2. provide for the appointment in consultation with the Policy Committee of an Advisory Committee for Mathematics consisting of active mathematicians;

3. maintain proper contacts with other divisions of the National Research Council and with the Social Science Research Council, in order to secure an alert awareness of their needs for mathematics.

II. One of the most acute problems facing mathematics today is the publication problem. We strongly urge that explicit provision be 
made for offering subsidies to existing journals and for the support of new journals when the establishment of such journals is recommended by the Advisory Committee. The amount of subsidy should be determined on the basis of advice from the Advisory Committee. One possible scheme would be for the Foundation to allocate funds for subsidization of publications. The total sum might be a fixed percentage of the total grants made to individuals, universities, and so forth. In addition to this there are two other matters relating to publication which the Foundation should be requested to aid. These are:

A. The publication of historical or comprehensive surveys of various fields.

B. The regular publication of translations of articles in Russian and other unfamiliar languages.

III. A. General remarks-While some of the funds will be for specific projects on a contractual basis, in general it seems preferable to make grants to suitable individuals or universities. These grants would usually be made with the knowledge of an informal proposal, but such a proposal should not be intended to restrict studies too narrowly to programs laid down in advance. Annual reports by recipients of grants should be made to the Advisory Committee. This body should also advise on the renewal of grants. Grants for full time research should, in general, be for one year, renewable for a second year, and not normally renewable beyond that.

B. Assistance to libraries should be made to universities, and the funds should be administered by them.

C. Fellowships should be awarded for graduate and post-doctoral study and research on a national basis on recommendation of the Advisory Committee.

D. Grants to individuals should be made solely on the basis of individual merit without regard to field of research or age, and should be awarded on a national basis.

E. The Foundation should take as a major charge carefully selected attempts to assist an institution to develop its mathematics department according to plans proposed by the institution and approved by the Foundation. It may be desirable to have regional boards to advise on this feature of the problem. Contributions to sabbatical year salaries would be decided here.

F. Grants should be available for projects if group undertakings seem warranted.

IV. The Foundation should seek additional means of discovering and fostering promising mathematical talent among young students, 
particularly those who, for geographic or other reasons, may have only poor opportunities for discovering this talent for themselves. In particular, the Foundation should explore the desirability of publishing, or assisting the Mathematical Association to publish, a periodical for the benefit of secondary school students in order to stimulate and direct younger students showing definite mathematical ability and interest.

V. The Mathematics Division of the National Research Council, with financial assistance where needed from the National Science Foundation, should sponsor studies of the quality of teaching and the curriculum in mathematics at the secondary school level throughout the country, and take steps to bring about whatever changes are indicated as necessary by the study. Among other things, study should be made of the desirability of the development of visual and auditory aids to teaching. The writing of sound mathematics books at the secondary school level, and of good texts for undergraduates should be encouraged.

VI. The Foundation should consider from time to time additional activities, such as conferences on research fields of current interest. 